\title{
Study of the dynamics of the coefficient of external friction of seeds crops with shell
}

\author{
Igor Khozyaev ${ }^{1}$, Dmitriy Savenkov $^{1 *}$, Oleg Kirischiev ${ }^{1}$, Ylia Kirischieva ${ }^{1}$, Tatiana \\ Tupolskikh $^{1}$ \\ ${ }^{1}$ Don State Technical University, 1, pl. Gagarina, 344003, Rostov-on-Don, Russia
}

\begin{abstract}
The article is devoted to the study of the coefficients of external friction of grain agricultural products-friction in static and dynamic modes, as the most important physical and mechanical characteristics of bulk materials. The description of carousel laboratory unit, program, methodology and results of studies on the practical determination of the coefficients of external friction for typical agricultural grain products according to the materials typical of the working bodies of the production machines. As a result of the research, it was found that in the range of linear velocities from 0 to $1.75 \mathrm{~m} / \mathrm{s}$, there is a change in the friction coefficients, which has a nonlinear character.
\end{abstract}

\section{Introduction}

When designing agricultural machines, it is important to take into account the dynamic coefficient of friction of bulk material on the working bodies of agricultural machines. The nature of the process of interaction of bulk products with the working bodies of machines depends on the value of the static and dynamic coefficients of friction. Therefore, the correct calculation of the design parameters of the machines and the selection of their operating modes depend on the accuracy of determining the value of the friction coefficients. [1-4].

When determining the value of the static coefficient of external friction, there are no special difficulties. In the classical form, it is equal to the tangent of the angle of inclination of the surface at which the movement of the bulk material begins. When determining the value of the dynamic coefficient of external friction, many difficulties arise. This is due to the design of the device and the method of determination of coefficient First of all, it is necessary to ensure the uniform movement of the bulk material on the surface and at the same time still change the speed of movement. After all, the coefficient of dynamic friction itself depends on the value of the speed of movement of the bulk material relative to the surface. In this regard, the determination of the dynamics of the coefficient of friction of seed crops is an urgent task.

The purpose of this study is to identify the dynamics of changes in the coefficient of external friction of seed crops on surfaces made of materials typical for the working bodies of agricultural machines.

\footnotetext{
* Corresponding author: savenkov-dstu@yandex.ru
} 


\section{Materials and methods}

To achieve the goal of the study, a carousel-type installation was used to determine the dynamics of changes in the external coefficient of friction of bulk materials. The working body of this device is a driven, rotating cup, the end face of which is covered with the test material, and a holder for the bulk product, which is mounted on the cup with the possibility of free rotation. The holder has radial integrated blades and is connected to the dynamometer, Figure 1. In such a device, the product is guaranteed to shift relative to the test surface due to the presence of blades that exclude uncontrolled product shift relative to the holder. The value of the shear force that occurs at the boundary between the rotating cup and the stationary holder measured by the dynamometer allows us to determine the coefficient of friction by the calculated method [5-8].

Fig. 1 shows a general view of the installation for determining the effect of the displacement rate of grain bulk material on the coefficient of dynamic friction on a stationary surface.

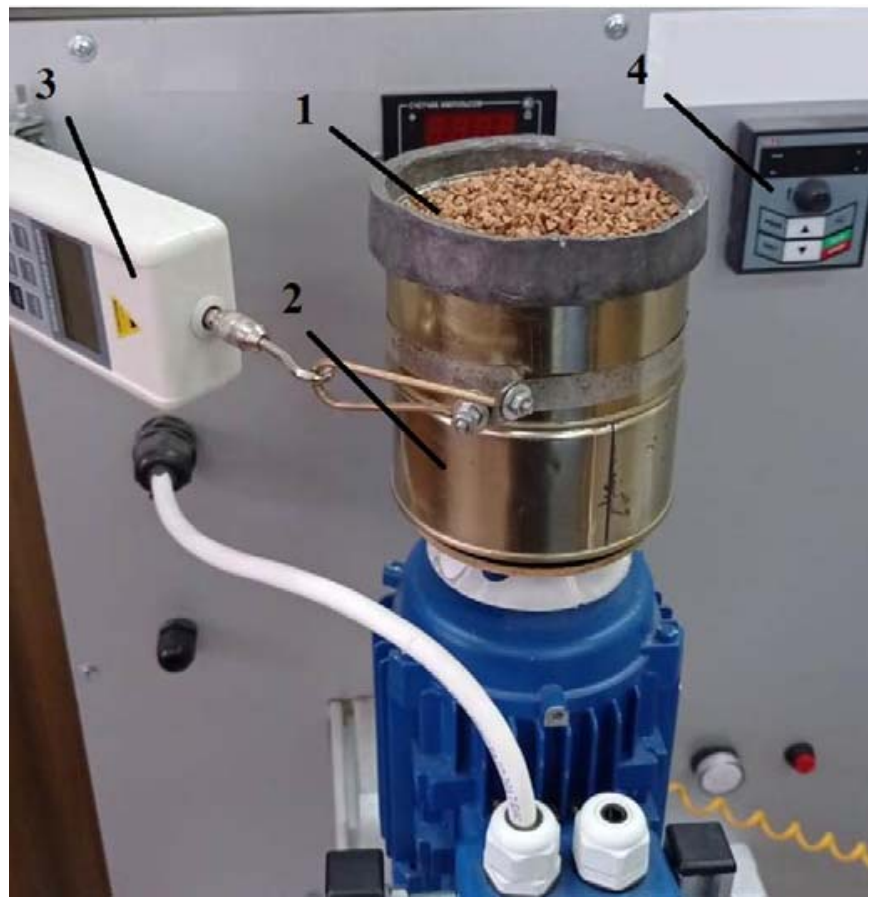

Fig. 1. The general view of the device for determining the dynamics of changes in the coefficient of external friction of bulk materials. 1 - holder of friction device; 2 - cup; 3 -dynamometer; 4 - the regulator of speed of rotation of the cup.

The main property of this installation is to ensure the accuracy of the results of studies of the friction characteristics of bulk materials: the coefficient of external friction of rest and the coefficient of external friction of the movement of bulk material on various rigid materials.

From the general variety of installations for determining the friction characteristics of bulk materials, the developed installation differs in that it allows you to obtain data on the coefficients of friction at speeds that are achieved in real conditions of processing grain products [9-11].

When conducting research, a sample of the test material is placed on the end face of the cup, and the grain product is filled into the holder. The fixed holder is connected to a 
dynamometer with a digital display to display the values of the force of interaction of the grain with the surface of the material.

The linear velocity of the grain displacement on the test surface is determined by calculation based on the data on the speed of rotation of the cup.

In the first stage, a study of the dependence of the force on the dynamometer speed Cup without downloading holder of the investigational product, which allowed to determine the correction characteristic in dependence of the efforts of the idle setup due to its design. The correction is defined as the amount of force on the dynamometer $(\mathrm{N})$ at a given speed of rotation of the cup (v), loaded only by the self-weight of the holder [12-15].

As a result of the conducted studies, it was found that in the range of rotation speeds $\mathrm{v}$ from 0 to $500 \mathrm{~min}-1$, the idling force of the installation does not change significantly and ranges from 0.55 to $0.65 \mathrm{~N}$. The average force value of $0.625 \mathrm{~N}$ is taken as the idling value for correcting the results of studies with grain products. The correction for measuring the static coefficient of friction at $\mathrm{v}=0$ is not applied $(\mathrm{N}=0)$.

\section{Results}

The determination of external friction coefficients was carried out on typical agricultural grain products, which was placed on materials typical for the working bodies of production machines.

During the experiments, grain crops were used: buckwheat, which has a fruit-nut, and safflower with an achene fruit. The typical materials of the working bodies were polished steel and plastic.

Methods of conducting experiments: blades.

1. A sample of the test material is placed at the cup end face up to the level of the holder

2. A measured portion of the test product with a mass of $m$ is filled into the holder.

3. The cup rotation drive activated.

4. The set speed is setted.

5. The force on the dynamometer (Y) is measured at least 3 times in 30 seconds and the results are recorded in the $\log$.

The static coefficient of friction is measured at the moment corresponding to the initial displacement of the cup. That is, the shear force corresponding to the zero displacement velocity is measured. Further experiments are carried out at discrete values of the speed of rotation of the cup, which are set based on the design capabilities of the installation. The maximum speed achieved during the experiments is $500 \mathrm{~min}-1$, which corresponds to a linear velocity of $1.57 \mathrm{~m} / \mathrm{s}$.

Upon completion of the experiments, the following procedures are performed for each grain product:

1. The average value of the force on the dynamometer $\mathrm{Y}$ is calculated at a given speed.

2. The idle speed of the unit force correction is made and the force on the dynamometer (T) corresponding to the friction force is determined.

3. The friction force $(F)$ is calculated from the condition of balancing the moment of the friction force by the moment of force on the dynamometer

$$
F=T \frac{3 R}{2 r} \quad,
$$

where: $\mathrm{R}$ - the radius of the attachment point of the dynamometer to the holder $(\mathrm{R}=60$ $\mathrm{mm}), \mathrm{r}$ - the radius of the holder $(\mathrm{r}=50 \mathrm{~mm})$.

4. The linear velocity $(\mathrm{V})$ of the center of mass of the portion of material is calculated. 
5. The value of the dynamic coefficient of friction $(\mathrm{k})$ for each speed is calculated by the formula:

$$
\mathrm{k}=\mathrm{F} / \mathrm{N} \text {, }
$$

where: $\mathrm{N}$ - weight of the material portion in the holder.

6. For each product and material the models of the dependence $k=f(V)$ are constructed.

7. In order to obtain information about changes in the tribological characteristics of bulk products in dynamics in a more familiar form for the user, the friction angles $(\varphi)$ are calculated for each product according to the known formula [16]:

$$
\phi=\operatorname{arctg}(k) \text {. }
$$

\section{Discussion of the results}

The results of experiments to determine the dependence of the dynamic coefficient of friction on the speed of movement of grain products are presented in the form of tables 1-4 and graphs 2-5. In the graphs, the function $k=f(V)$ is represented in the entry $y=f(x)$

In the course of the research the following results were obtained, tables 1-4:

Table 1. Coefficients of friction of safflower on steel.

\begin{tabular}{|c|c|c|c|}
\hline Test & $\begin{array}{c}\text { Rotational } \\
\text { speed, } \mathrm{m}^{-1}\end{array}$ & $\mathrm{k}$ & $\varphi$, degree \\
\hline 1 & 0,000 & 0,04 & 2,3 \\
\hline 2 & 0,175 & 0,42 & 22,8 \\
\hline 3 & 0,45 & 0,73 & 36,1 \\
\hline 4 & 0,70 & 1,19 & 50,0 \\
\hline 5 & 0,91 & 1,31 & 52,6 \\
\hline 6 & 1,12 & 1,92 & 62,5 \\
\hline 7 & 1,36 & 2,19 & 65,5 \\
\hline 8 & 1,57 & 2,29 & 66,4 \\
\hline
\end{tabular}

Table 2. Coefficients of friction of safflower on steel.

\begin{tabular}{|c|c|c|c|}
\hline Test & $\begin{array}{c}\text { Rotational } \\
\text { speed, } \mathrm{m}^{-1}\end{array}$ & $\mathrm{k}$ & $\varphi$, degree \\
\hline 1 & 0,000 & 0,01 & 0,6 \\
\hline 2 & 0,175 & 0,04 & 2,3 \\
\hline 3 & 0,45 & 0,16 & 9,1 \\
\hline 4 & 0,70 & 0,68 & 34,2 \\
\hline 5 & 0,91 & 0,85 & 40,4 \\
\hline 6 & 1,12 & 1,04 & 46,1 \\
\hline 7 & 1,33 & 1,49 & 56,1 \\
\hline 8 & 1,54 & 1,56 & 57,3 \\
\hline
\end{tabular}

As a result of modeling the following dependences are obtained, figure 2-3: 


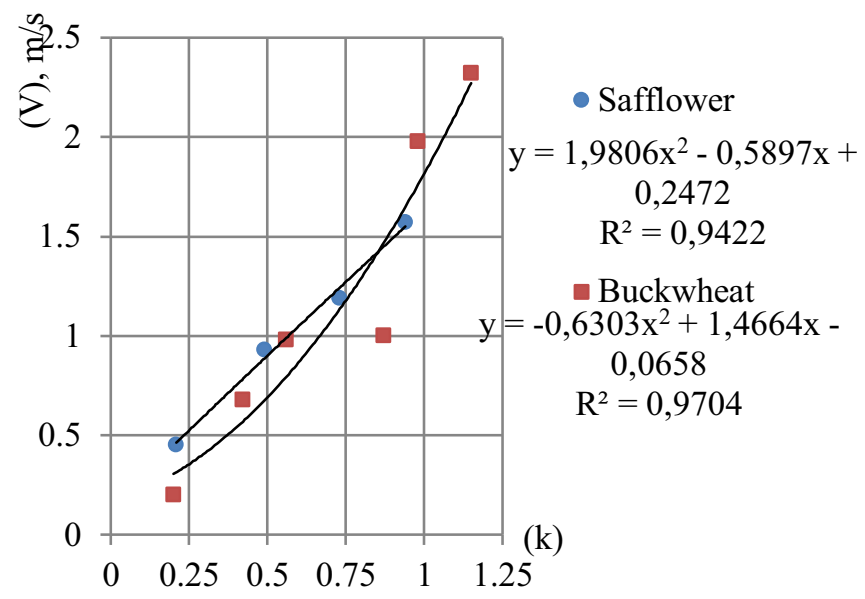

Fig. 2. Dependence of the coefficient of friction of safflower and buckwheat on steel.

Table 3. Coefficients of friction of safflower on plastic.

\begin{tabular}{|c|c|c|c|}
\hline Test & $\begin{array}{c}\text { Rotational } \\
\text { speed, } \mathrm{m}^{-1}\end{array}$ & $\mathrm{k}$ & $\varphi$, degree \\
\hline 1 & 0,209 & 0,25 & 14,0 \\
\hline 2 & 0,49 & 0,93 & 42,9 \\
\hline 3 & 0,73 & 1,19 & 50,0 \\
\hline 4 & 0,94 & 1,57 & 57,5 \\
\hline
\end{tabular}

Table 4. Coefficients of friction of buckwheat on plastic.

\begin{tabular}{|c|c|c|c|}
\hline Test & $\begin{array}{c}\text { Rotational } \\
\text { speed, } \mathrm{m}^{-1}\end{array}$ & $\mathrm{k}$ & $\varphi$, degree \\
\hline 1 & 0,000 & 0,35 & 19,3 \\
\hline 2 & 0,42 & 0,68 & 34,2 \\
\hline 3 & 0,56 & 0,98 & 44,4 \\
\hline 4 & 0,87 & 1,00 & 45,0 \\
\hline 5 & 0,98 & 0,98 & 44,4 \\
\hline 6 & 1,15 & 2,32 & 66,7 \\
\hline
\end{tabular}




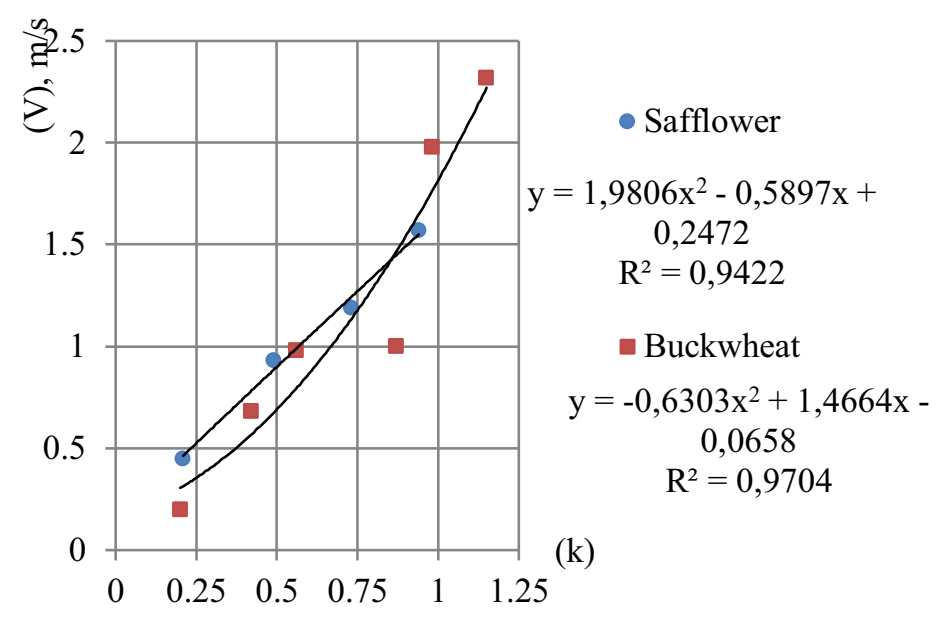

Fig. 3. Dependence of the coefficient of friction of safflower and buckwheat on plastic.

\section{Conclusions}

1. The dependence of the external friction coefficients of typical agricultural grain products about the materials typical for the working bodies of production machines on the displacement velocity in the range from 0 to $1.57 \mathrm{~m} / \mathrm{s}$ is nonlinear.

2. The values of $\mathrm{k}$ that are closest to real data for all materials give second-order polynomial models:

\begin{tabular}{|c|c|c|}
\hline Product & Surface & Model \\
\hline \multirow{2}{*}{ Safflower } & Steel & $\mathrm{y}=-0,127 \mathrm{x}^{2}+1,674 \mathrm{x}+0,058, \mathrm{R}^{2}=0,984$ \\
\cline { 2 - 3 } & Plastic & $\mathrm{y}=-0,836 \mathrm{x}^{2}+2,700 \mathrm{x}-0,259, \mathrm{R}^{2}=0,987$ \\
\hline \multirow{2}{*}{ Buckwheat } & Steel & $\mathrm{y}=-0,344 \mathrm{x}^{2}+1,965 \mathrm{x}-0,621, \mathrm{R}^{2}=0,974$ \\
\cline { 2 - 3 } & Plastic & $\mathrm{y}=-0,698 \mathrm{x}^{2}+1,363 \mathrm{x}+0,334, \mathrm{R}^{2}=0,932$ \\
\hline
\end{tabular}

3. The device of carousel type for determination of frictional characteristics of bulk materials allows to score problems of practical determination of dynamic coefficients of friction of the investigated bulk products of agricultural production in the range of speeds from 0 to $1.57 \mathrm{~m} / \mathrm{s}$ with reliability $\mathrm{R}^{2}$ not lower then 0.932 .

\section{References}

1. A. Doroshenko, MATEC Web Conf., 224, 05023 (2018)

2. X. Liu, Journal of Materials Science \& Technology, 35, 1412-1421 (2019)

3. H. Baek, International Journal of Solids and Structures, 144-145, 86-99 (2018)

4. C. Menapace, Wear, 398-399, 191-200 (2018)

5. K. Saw, Materailstoday: Processing, 5, 24094-24103 (2018)

6. D. Savenkov, MATEC Web Conf., 224, 05023 (2018)

7. D. Savenkov, E3S Web Conf., 135, 01102 (2019)

8. K. Senetakis, Tribology International, 111, 1-8 (2017) 
9. A. Vakis, Tribology International, 125, 169-199 (2018)

10. S. Zhang, Materailstoday (2018)

11. U. Nirmal, Tribology International, 83, 77-104 (2015)

12. T. Mills, Woodhead Publishing Series in Food Science, Technology and Nutrition, 292-309 (2013)

13. B. Winkeljann, Biotribology, 14, 11-18 (2018)

14. P. Udaykant, Tribology International, 126, 240-248 (2018)

15. Yu. A. Ivanov, MATEC Web Conf., 224, 05023 (2018)

16. S. I. Kambulov, MATEC Web Conf., 224, 05022 (2018) 